\title{
The hepato-protective effect of eupatilin on an alcoholic liver disease model of rats
}

\author{
Hak Yeong Lee", Yoonjin Nam", Won Seok Choi", Tae Wook Kim, Jaehwi Lee, and Uy Dong Sohn* \\ College of Pharmacy, Chung-Ang University, Seoul 06974, Korea
}

\section{ARTICLE INFO}

Received January 3, 2020

Revised June 17, 2020

Accepted June 18, 2020

*Correspondence

Uy Dong Sohn

E-mail: udsohn@cau.ac.kr

\section{Key Words}

Alcoholic liver disease

Ethanol

Eupatilin

Inflammation

Oxidative stress

\#These authors contributed equally to this work.

\begin{abstract}
Eupatilin is known to possess anti-apoptotic, anti-oxidative, and antiinflammatory properties. We report here that eupatilin has a protective effect on the ethanol-induced injury in rats. Sprague-Dawley rats were divided into 6 groups: control, vehicle, silymarin, eupatilin $10 \mathrm{mg} / \mathrm{kg}$, eupatilin $30 \mathrm{mg} / \mathrm{kg}$, and eupatilin 100 $\mathrm{mg} / \mathrm{kg}$. Plasma levels of aspartate aminotransferase (AST) and alanine aminotransferase (ALT) were analyzed to determine the extent of liver damage. Total cholesterol (TC) and triglycerides (TG) were analyzed to determine the level of liver steatosis. Malondialdehyde level, superoxide dismutase (SOD) activity, and glutathione (GSH) level were analyzed to determine the extent of oxidative stress. Tumor necrosis factor (TNF)- $\alpha$ and interleukin (IL)-1 $\beta$ were quantified to verify the degree of inflammation. Based on our findings, chronic alcohol treatment significantly changed the serum indexes and liver indicators of the model rats, which were significantly improved by eupatilin treatment. Rats in the eupatilin-treatment group showed reduced levels of AST, ALT, TG, TC, TNF- $\alpha$, and IL- $1 \beta$, increased SOD activity and GSH levels, and improved overall physiology compared to the alcoholic liver disease model rats. H\&E staining also verified the eupatilin-mediated improvement in liver injury. In conclusion, eupatilin inhibits alcohol-induced liver injury via its antioxidant and anti-inflammatory effects.
\end{abstract}

\section{INTRODUCTION}

The liver is the main organ that metabolizes ethanol. As a result, it can easily be damaged by alcohol ingestion [1]. Alcohol metabolites and increased oxidative stress are associated with the promotion of hepatic injury [2]. The liver has two enzymes-dehydrogenase and cytochrome P450 2E1 (CYP2E1)-for metabolizing alcohol [3]. The metabolism proceeded by alcohol dehydrogenase produces acetaldehyde [4]. CYP2E1 produces highly reactive oxygen and acetaldehyde, which induce oxidative stress and increase lipids. CYP2E1 can produce other highly reactive intermediates and malondialdehyde (MDA) [5]. Similar to acetaldehyde, these CYP2E1-generated metabolites form covalent, stable complexes with lipids, DNA, proteins, and other macromolecules. Therefore, in alcohol-induced hepatotoxicity, the covalent modifications during chronic alcohol ingestion is suggested to inhibit the normal function of hepatic lipids, DNA, and protein, thereby inducing hepatocyte dysfunction and damage [6].

Continued alcohol ingestion can cause alcoholic liver disease (ALD), including alcoholic hepatitis, alcoholic fibrosis, and alcoholic cirrhosis. Excessive alcohol intake can also cause severe liver damage [7]. ALD is reported to involve increased oxidative stress because of decreased antioxidant enzymes such as glutathione (GSH), as well as inflammation, fat accumulation, and hepatic mitochondrial injury [8]. Variation in the amounts of lipid deposits in liver cells is a common feature of alcoholic fatty liver. Chronic alcohol intake was reported to increase cholesterol, triglyceride (TG) accumulation, and the subsequent substrate in

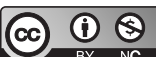

This is an Open Access article distributed under the terms of the Creative Commons Attribution Non-Commercial License, which permits unrestricted non-commercial use, distribution, and reproduction in any medium, provided the original work is properly cited. Copyright @ Korean J Physiol Pharmacol, pISSN 1226-4512, elSSN 2093-3827
Author contributions: U.D.S. organized and supervised all procedures. H.Y.L. and Y.N. performed data analysis and revised the work protocol and manuscript. W.S.C., T.W.K., and J.L. participated in research design and contributed the analytical techniques and tools. H.Y.L. and Y.N. conducted experiments, including design, and contributed to the writing of the manuscript. 
the liver tissue [9]. Therefore, reducing TG and cholesterol might contribute to the treatment of ALD.

An improvement in abnormal immune system induced by ALD was reported to have beneficial effect on ALD-induced liver damage [10]. In particular, increased hepatocyte necrosis has been found to occur during exposure to alcohol [11]. Inflammation plays a key role in ALD via reactive oxygen species formation $[12,13]$. In accordance with a previous study, chronic alcohol ingestion was found to increase pro-inflammatory cytokines, such as tumor necrosis factor- $\alpha$ (TNF- $\alpha$ ), interleukin-1 $\beta$ (IL-1 $\beta$ ), and other chemokines [14].

5,7-Dihydroxy-3',4',6-trimethoxyflavone (eupatilin) is a pharmacologically active flavone extracted from an Artemisia species [15]. Eupatilin is known to have several pharmacological properties, such as anti-oxidative, anti-apoptosis, and anti-inflammatory $[16,17]$. Additionally, it exhibits therapeutic effects on gastritis and peptic ulcers associated with different cytokines and neuropeptides that can affect gastrointestinal motility [18], gastric mucosal damage [19], cerulein-induced pancreatitis [20], dextran sulfate sodium-induced colitis [21], and reflux esophagitis [22]. Acetaminophen or carbon tetrachloride was also demonstrated to reduce liver damage in animal experiments on liver injury [23] and cholestatic liver diseases [24]. However, the inhibitory effect of eupatilin has not been evaluated using an ALD model.

In this study, we explored the hepato-protective effects of eupatilin on ALD model in aspects of antioxidant and anti-inflammatory effects.

\section{METHODS}

\section{Animals}

Male Sprague-Dawley rats (age, 7 weeks old) were purchased from Raon Bio (Yongin, Korea). Rats were housed under standard laboratory conditions (temperature, $23^{\circ} \mathrm{C}-25^{\circ} \mathrm{C}$; and humidity, $70 \%-75 \%$ ) in a controlled room under a $12 / 12 \mathrm{~h}$ light/dark cycle, with free access to tap water and food. All animal experiments were approved by the Institute Animal Care and Use Committee (IACUC) of Chung-Ang University in accordance with the guide for the Care and Use of Laboratory Animals in Seoul, Korea (IACUC-2018-00005).

\section{Materials}

Eupatilin was provided by Dong-A Pharmaceutical Co., Ltd. (Yongin, Korea). Silymarin was purchased from Sigma-Aldrich Chemical Co. (St. Louis, MO, USA). Both drugs were dissolved in $0.1 \%$ carboxy methylcellulose sodium (CMC-Na), purchased from Sigma-Aldrich Chemical Co. Absolute ethanol was purchased from Duksan Co. (Ansan, Korea).

\section{Experimental design}

Sprague-Dawley rats were randomly divided into the following 6 experimental groups ( $\mathrm{n}=6$ in each group): 1) control group, administered saline and $0.1 \% \mathrm{CMC}-\mathrm{Na} ; 2$ ) vehicle group, administered $7 \mathrm{~g} / \mathrm{kg}$ ethanol and $0.1 \% \mathrm{CMC}-\mathrm{Na} ; 3$ ) silymarin (positive control) group, administered $7 \mathrm{~g} / \mathrm{kg}$ ethanol and silymarin 10 $\mathrm{mg} / \mathrm{kg}$, a generally used hepatoprotective agent [25]; 4) eupatilin $10 \mathrm{mg} / \mathrm{kg}$, administered $7 \mathrm{~g} / \mathrm{kg}$ ethanol and eupatilin $10 \mathrm{mg} / \mathrm{kg} ; 5$ ) eupatilin $30 \mathrm{mg} / \mathrm{kg}$, administered $7 \mathrm{~g} / \mathrm{kg}$ ethanol and eupatilin 30 $\mathrm{mg} / \mathrm{kg}$; and 6) eupatilin $100 \mathrm{mg} / \mathrm{kg}$, administered $7 \mathrm{~g} / \mathrm{kg}$ ethanol and eupatilin $100 \mathrm{mg} / \mathrm{kg}$. The concentrations of eupatilin were retrieved from a previous study [23]. Ethanol was orally administered to rats in the ALD model groups once daily for 42 days. The ALD model was established by the oral administration of $70 \%$ ethanol $(7 \mathrm{~g} / \mathrm{kg})$. Saline and ethanol were orally administered $4 \mathrm{~h}$ before the administration of the vehicle, eupatilin, or silymarin. Eupatilin and silymarin were suspended in a 0.1\% CMC-Na solution for treatment. All reagents were freshly prepared prior to use.

\section{Preparation of blood samples and hepatic tissues}

After the final administration, rats were anesthetized using diethyl ether (Duksan Co.) and sacrificed. Blood was obtained from the inferior vena cava for biochemical experiments and stored in a vacutainer (BD; Beliver Industrial ESTATE, Plymouth, UK). Samples were centrifuged at $1,300 \mathrm{~g}$ for $10 \mathrm{~min}$ at room temperature for plasma collection. Following blood collection, the liver was immediately extracted. The plasma was stored at $-70^{\circ} \mathrm{C}$ until use and the liver tissues were stored in 10\% formalin.

\section{Analysis of metabolic index}

The Toshiba Accute Biochemical Analyzer-TBA-40FR (Toshiba Medical Instruments, Shimoishigami, Japan) was used to derive the metabolic index. Aspartate aminotransferase (AST) and alanine aminotransferase (ALT) were analyzed as indicators for liver function. TG and total cholesterol (TC) were measured as indicators for liver steatosis. All reagents for this procedure were purchased from Chema Diagnostica (Monsano, Italy).

\section{Lipid peroxidation}

Lipid peroxidation was analyzed by measuring MDA production using the MDA ELISA kit for rats (E-EL-0060; Elabscience, Wuhan, China). Briefly, $50 \mu \mathrm{l}$ of the standard or sample and the same volume of biotinylated detection antibody were added to each well. Thereafter, incubation was performed for $45 \mathrm{~min}$ followed by aspiration and 3 rounds of washing. A $100 \mu$ l volume of the HRP conjugate was added to each well and incubated for $30 \mathrm{~min}$. Thereafter, the wells were aspirated, washed 5 times, and treated with $90 \mu \mathrm{l}$ of the substrate reagents. After incubation for 
$15 \mathrm{~min}, 50 \mu \mathrm{l}$ of the stop solution was added and absorbance was measured at $450 \mathrm{~nm}$.

\section{SOD activity}

Superoxide dismutase (SOD) activity was analyzed with the SOD ELISA kit (ab65354; Abcam, Cambridge, MA, USA). Briefly, $20 \mu \mathrm{l}$ of the standard or sample and $200 \mu \mathrm{l}$ of the WST working solution were added to each well. The rate of WST-1 reduction is known to mediate the inhibitory activity of xanthine oxidase by SOD in a linear manner. After the addition of $20 \mu \mathrm{l}$ of the dilution buffer and enzyme working solution to each well, incubation was conducted for $20 \mathrm{~min}$ followed by the measurement of absorbance at $450 \mathrm{~nm}$.

\section{GSH concentration}

GSH was analyzed using the GSH ELISA kit for rats (E-EL0026; Elabscience). Briefly, $50 \mu \mathrm{l}$ of the standard or sample and the same volume of biotinylated detection antibody were added to each well. Thereafter, incubation was performed for $45 \mathrm{~min}$ followed by aspiration and 3 rounds of washing. A $100 \mu$ l volume of the HRP conjugate was added to each well and incubated for $30 \mathrm{~min}$. Thereafter, the wells were aspirated, washed 5 times, and treated with $90 \mu \mathrm{l}$ of the substrate reagents. After incubation for $15 \mathrm{~min}, 50 \mu \mathrm{l}$ of the stop solution was added to each well, and absorbance was measured at $450 \mathrm{~nm}$.

\section{TNF- $\alpha$ concentration}

TNF- $\alpha$ concentration was measured using a TNF- $\alpha$ ELISA kit for rats (E-EL-R0019; Elabscience). Briefly, $100 \mu \mathrm{l}$ of the standard or sample was added to each well and incubated for $90 \mathrm{~min}$. After the removal of the liquid, the wells were replenished with the same amount of biotinylated detection antibody. Thereafter, incubation was carried out for $1 \mathrm{~h}$ followed by aspiration and 3 rounds of washing. A $100 \mu \mathrm{l}$ volume of the HRP conjugate was added to each well and incubated for $30 \mathrm{~min}$. Thereafter, the wells were aspirated, washed 5 times, and treated with $90 \mu$ of the substrate reagent. After incubation for $15 \mathrm{~min}, 50 \mu \mathrm{l}$ of the stop solution was added, and absorbance was measured at $450 \mathrm{~nm}$.

\section{IL-1 $\beta$ concentration}

IL-1 $\beta$ concentration was analyzed using an IL-1 $\beta$ ELISA kit for rats (E-EL-R0012; Elabscience). Briefly, $100 \mu \mathrm{l}$ of the standard or sample was added to each well and incubated for $90 \mathrm{~min}$. After removal of the liquid, the same amount of biotinylated detection antibody was added to each well. Incubation was then performed for $1 \mathrm{~h}$ followed by aspiration and 3 rounds of washing. A $100 \mu \mathrm{l}$ volume of the HRP conjugate was to each well and incubated for $30 \mathrm{~min}$. Thereafter, the wells were aspirated, washed 5 times, and treated with $90 \mu$ of the substrate reagent. After incubation for 15 min, $50 \mu$ lof the stop solution was added to each well, and absorbance was measured at $450 \mathrm{~nm}$.

\section{Histological evaluation}

Liver tissues were extracted and fixed with $10 \%$ formalin and dehydrated with $70 \%$ ethanol. After each tissue was embedded with paraffin, $5 \mu \mathrm{m}$ sections were dyed using hematoxylin \& eosin (H\&E) to detect damage. The stained tissues were captured with a Leica DM IL LED (Wetzlar, Germany). Magnified images were photographed at $20 \times$ and $40 \times$ magnifications.

\section{Data analysis}

Data are expressed as mean \pm standard error of the mean. Statistical differences among the groups were analyzed by oneway ANOVA. If the p-value was less than 0.05 , the difference was considered statistically significant. Statistical procedures were performed using Prism-Graph Pad (GraphPad Software Inc., San Diego, CA, USA).

\section{RESULTS}

\section{Eupatilin restored weight loss in the ALD model}

Rats were weighed immediately following the start of the experiment and after 42 days (Fig. 1). Six weeks after the experiment, rats in the vehicle group were found to weigh less than

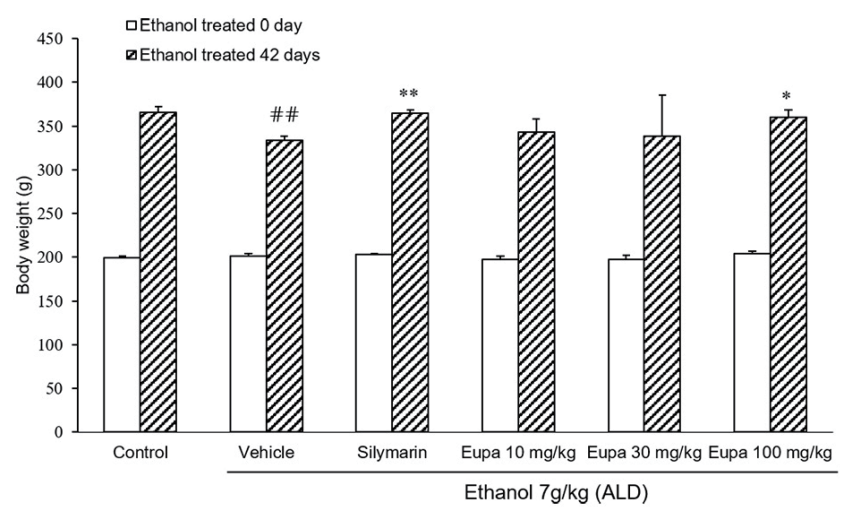

Fig. 1. Eupatilin restored weight loss in the alcoholic liver disease model. Body weights of rats $(n=7)$ were measured. Control group: saline + 0.1\% CMC-Na, vehicle group: $7 \mathrm{~g} / \mathrm{kg}$ ethanol + 0.1\% CMC-Na, silymarin (positive control) group: $7 \mathrm{~g} / \mathrm{kg}$ ethanol + silymarin $10 \mathrm{mg} / \mathrm{kg}$, eupatilin $10 \mathrm{mg} / \mathrm{kg}: 7 \mathrm{~g} / \mathrm{kg}$ ethanol + eupatilin $10 \mathrm{mg} / \mathrm{kg}$, eupatilin 30 $\mathrm{mg} / \mathrm{kg}: 7 \mathrm{~g} / \mathrm{kg}$ ethanol + eupatilin $30 \mathrm{mg} / \mathrm{kg}$, and eupatilin $100 \mathrm{mg} / \mathrm{kg}$ : $7 \mathrm{~g} / \mathrm{kg}$ ethanol + eupatilin $100 \mathrm{mg} / \mathrm{kg}$. Data are expressed as mean \pm standard error of the mean. CMC-Na, sodium carboxymethyl cellulose; ALD, alcoholic liver disease. ${ }^{* \#} \mathrm{p}<0.01$ vs. control group, ${ }^{*} \mathrm{p}<0.05$, ${ }^{* *} \mathrm{p}<$ 0.01 vs. vehicle group. 
those in the control group. Body weight was also found to significantly recover in the silymarin group, which was used as positive control. A significant recovery in weight did not occur in the eupatilin $10 \mathrm{mg} / \mathrm{kg}$ and $30 \mathrm{mg} / \mathrm{kg}$ groups compared to the vehicle group. Eupatilin $100 \mathrm{mg} / \mathrm{kg}$ treatment, similar to the silymarin group, could significantly restore weight relative to the vehicle.

\section{Eupatilin relieved liver damage in the ALD model}

AST and ALT were measured to investigate the degree of liver injury. The levels of AST are presented in Fig. 2A. AST level was increased in the vehicle group relative to the control group. How-

A

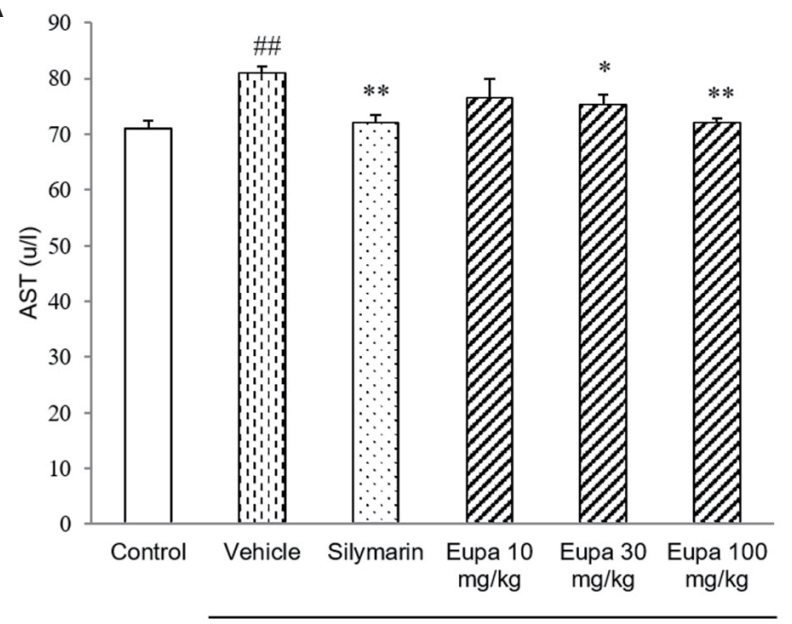

B

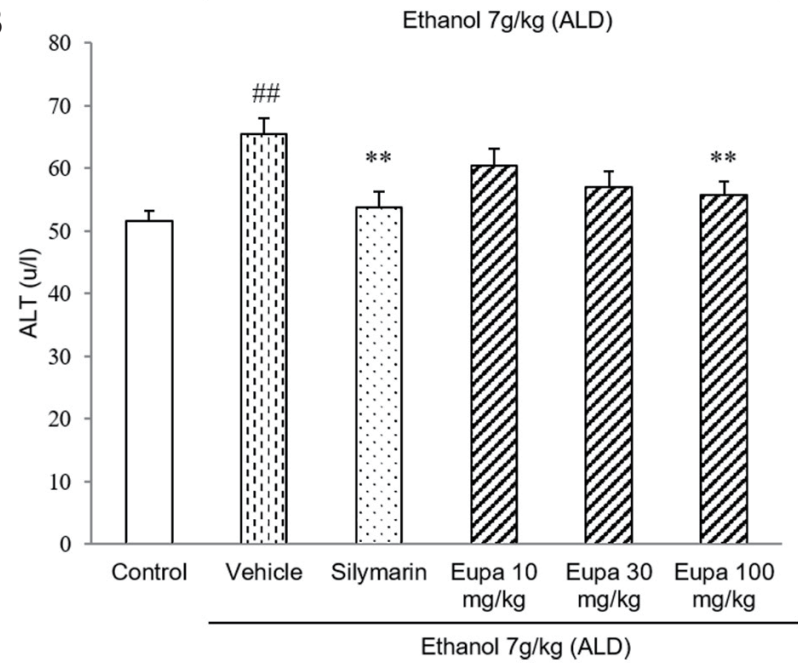

Fig. 2. Eupatilin reduced plasma AST and ALT in the alcoholic liver disease model. (A) AST and (B) ALT levels were measured in the rat plasma $(n=7)$. Control group: saline $+0.1 \%$ CMC-Na, vehicle group: 7 $\mathrm{g} / \mathrm{kg}$ ethanol + 0.1\% CMC-Na, silymarin (positive control) group: $7 \mathrm{~g} /$ $\mathrm{kg}$ ethanol + silymarin $10 \mathrm{mg} / \mathrm{kg}$, eupatilin $10 \mathrm{mg} / \mathrm{kg}: 7 \mathrm{~g} / \mathrm{kg}$ ethanol + eupatilin $10 \mathrm{mg} / \mathrm{kg}$, eupatilin $30 \mathrm{mg} / \mathrm{kg}: 7 \mathrm{~g} / \mathrm{kg}$ ethanol + eupatilin 30 $\mathrm{mg} / \mathrm{kg}$, and eupatilin $100 \mathrm{mg} / \mathrm{kg}: 7 \mathrm{~g} / \mathrm{kg}$ ethanol + eupatilin $100 \mathrm{mg} /$ $\mathrm{kg}$. Data are expressed as mean \pm standard error of the mean. CMC-Na, sodium carboxymethyl cellulose; ALD, alcoholic liver disease; AST, aspartate aminotransferase; ALT, alanine aminotransferase. ${ }^{\# \#} p<0.01$ vs. control group, ${ }^{*} p<0.05,{ }^{* *} p<0.01 v s$. vehicle group. ever, in the silymarin group, its level was significantly decreased relative to that in the vehicle group. Eupatilin $30 \mathrm{mg} / \mathrm{kg}$ and eupatilin $100 \mathrm{mg} / \mathrm{kg}$ groups showed lower levels of AST compared to vehicle group. In the case of eupatilin $100 \mathrm{mg} / \mathrm{kg}$ group, it showed the similar level of AST as the silymarin group. The levels of ALT of all groups are presented in Fig. 2B. ALT level was increased in the vehicle group. However, in the silymarin group, its level was decreased relative to that in the vehicle group. The eupatilin 30 $\mathrm{mg} / \mathrm{kg}$ and $100 \mathrm{mg} / \mathrm{kg}$ groups had a lower level of ALT compared to vehicle group. Eupatilin $100 \mathrm{mg} / \mathrm{kg}$ group showed a low level of ALT which was a similar level of the silymarin group.

TG and TC were measured to evaluate the degree of liver steatosis caused by liver damage. The TG levels in all groups are presented in Fig. 3A. TG level was increased in the vehicle group. However, in the silymarin group, TG level was decreased relative to that in the vehicle group. The eupatilin $30 \mathrm{mg} / \mathrm{kg}$ and $100 \mathrm{mg} /$
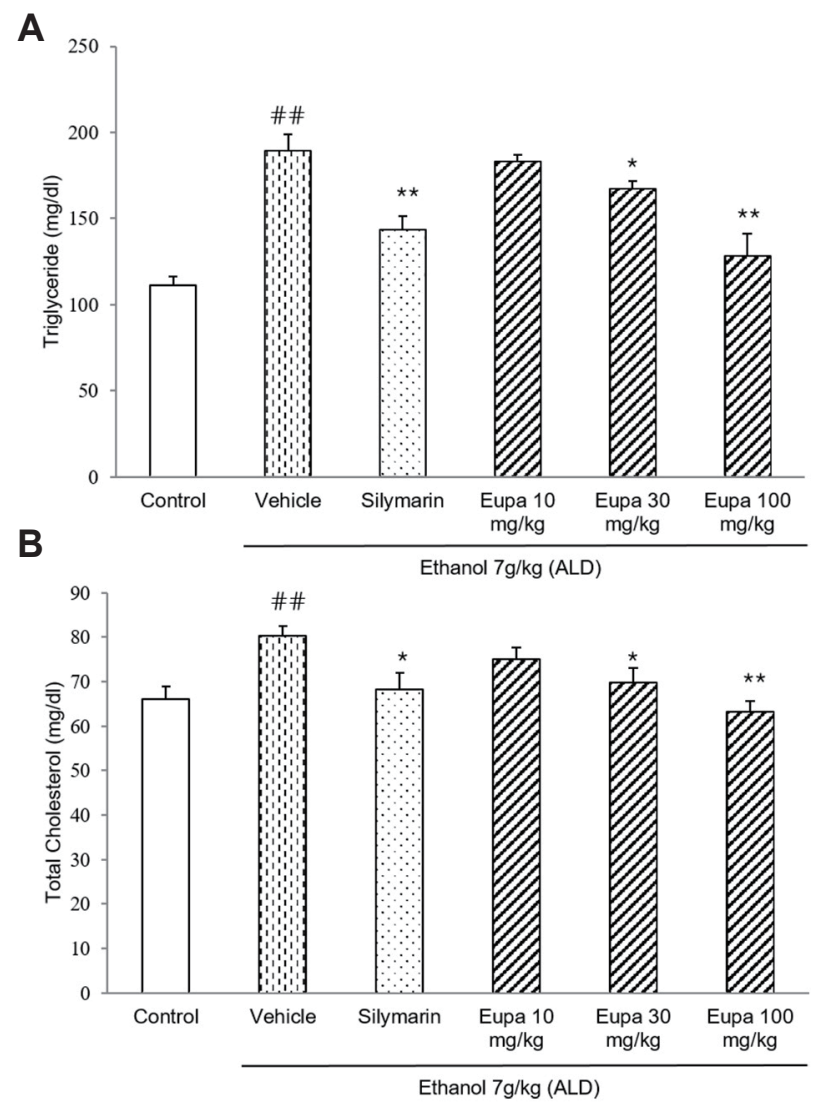

Fig. 3. Eupatilin reduced plasma TG and TC in the alcoholic liver disease model. (A) TG and (B) TC levels were measured in the rat plasma ( $\mathrm{n}$ = 7). Control group: saline $+0.1 \%$ CMC-Na, vehicle group: $7 \mathrm{~g} / \mathrm{kg}$ etha$\mathrm{nol}+0.1 \% \mathrm{CMC}-\mathrm{Na}$, silymarin (positive control) group: $7 \mathrm{~g} / \mathrm{kg}$ ethanol + silymarin $10 \mathrm{mg} / \mathrm{kg}$, eupatilin $10 \mathrm{mg} / \mathrm{kg}: 7 \mathrm{~g} / \mathrm{kg}$ ethanol + eupatilin $10 \mathrm{mg} / \mathrm{kg}$, eupatilin $30 \mathrm{mg} / \mathrm{kg}: 7 \mathrm{~g} / \mathrm{kg}$ ethanol + eupatilin $30 \mathrm{mg} / \mathrm{kg}$, and eupatilin $100 \mathrm{mg} / \mathrm{kg}: 7 \mathrm{~g} / \mathrm{kg}$ ethanol + eupatilin $100 \mathrm{mg} / \mathrm{kg}$. Data are expressed as mean \pm standard error of the mean. CMC-Na, sodium carboxymethyl cellulose; ALD, alcoholic liver disease; TG, triglyceride; TC, total cholesterol. ${ }^{\# \#} \mathrm{p}<0.01$ vs. control group, ${ }^{*} \mathrm{p}<0.05$, ${ }^{* *} \mathrm{p}<0.01$ vs. vehicle group. 
$\mathrm{kg}$ groups had lower levels of TG in the plasma. In eupatilin 100 $\mathrm{mg} / \mathrm{kg}$ group, TG level was reduced with a similar level of TG in silymarin group. The TC levels of all groups are presented in Fig. 3B. TC level was significantly increased in the vehicle group. In the silymarin group, TC level was decreased relative to the vehicle group. Eupatilin $30 \mathrm{mg} / \mathrm{kg}$ and eupatilin $100 \mathrm{mg} / \mathrm{kg}$ groups showed low levels of TC similar to the silymarin group. Thus, these results showed that both lipid profiles were recovered to near-control levels following eupatilin treatment.

\section{Eupatilin reduced plasma MDA and improved the antioxidant status in the ALD model}

MDA was measured to evaluate the degree of lipid peroxidation. MDA concentrations in all groups are presented in Fig. 4A. MDA level was increased in the vehicle group. However, in the silymarin group, MDA level was decreased relative to that in the vehicle group. Further, eupatilin $30 \mathrm{mg} / \mathrm{kg}$ and eupatilin $100 \mathrm{mg} /$ $\mathrm{kg}$ groups showed lower levels of MDA similar to the silymarin group.

SOD activity was measured to evaluate the enzymatic antioxidative effect of eupatilin. The SOD activity of all groups is presented in Fig. 4B. SOD activity was significantly decreased in the vehicle group but significantly increased in the silymarin group compared to that in the vehicle group. In Eupatilin $10 \mathrm{mg} /$ $\mathrm{kg}, 30 \mathrm{mg} / \mathrm{kg}$, and $100 \mathrm{mg} / \mathrm{kg}$ groups, SOD activity was increased in dose-dependent manner. Eupatilin $30 \mathrm{mg} / \mathrm{kg}$ and eupatilin 100 $\mathrm{mg} / \mathrm{kg}$ groups showed significantly increased SOD activity.

GSH was measured to evaluate the non-enzymatic antioxidant status in the plasma. The GSH concentrations of all groups are presented in Fig. 4C. GSH level was significantly decreased in the vehicle group but significantly increased in the silymarin group compared to that in the vehicle group. In addition, Eupatilin 100 $\mathrm{mg} / \mathrm{kg}$ group showed a significant increase in GSH level that was a similar result in the silymarin group.

\section{Eupatilin exhibited anti-inflammatory effects by reducing the level of inflammatory cytokines}

TNF- $\alpha$ was measured to evaluate the progression of ethanolinduced hepatotoxicity. The TNF- $\alpha$ concentrations of all groups are presented in Fig. 5A. TNF- $\alpha$ level was significantly increased in the vehicle group and significantly decreased in the silymarin group compared to that in the vehicle group. The eupatilin 30 $\mathrm{mg} / \mathrm{kg}$ and $100 \mathrm{mg} / \mathrm{kg}$ groups had lower levels of TNF- $\alpha$ compared to the silymarin group. Especially, eupatilin $100 \mathrm{mg} / \mathrm{kg}$ group showed similar level of TNF- $\alpha$ with the silymarin group.

IL-1 $\beta$ was measured to evaluate the anti-inflammatory effect of eupatilin. The IL-1 $\beta$ levels of all groups are presented in Fig. 5B. The IL-1 $\beta$ level was significantly increased in the vehicle group but decreased in the silymarin group compared to that in the vehicle group. Further, the eupatilin $30 \mathrm{mg} / \mathrm{kg}$ and $100 \mathrm{mg} / \mathrm{kg}$
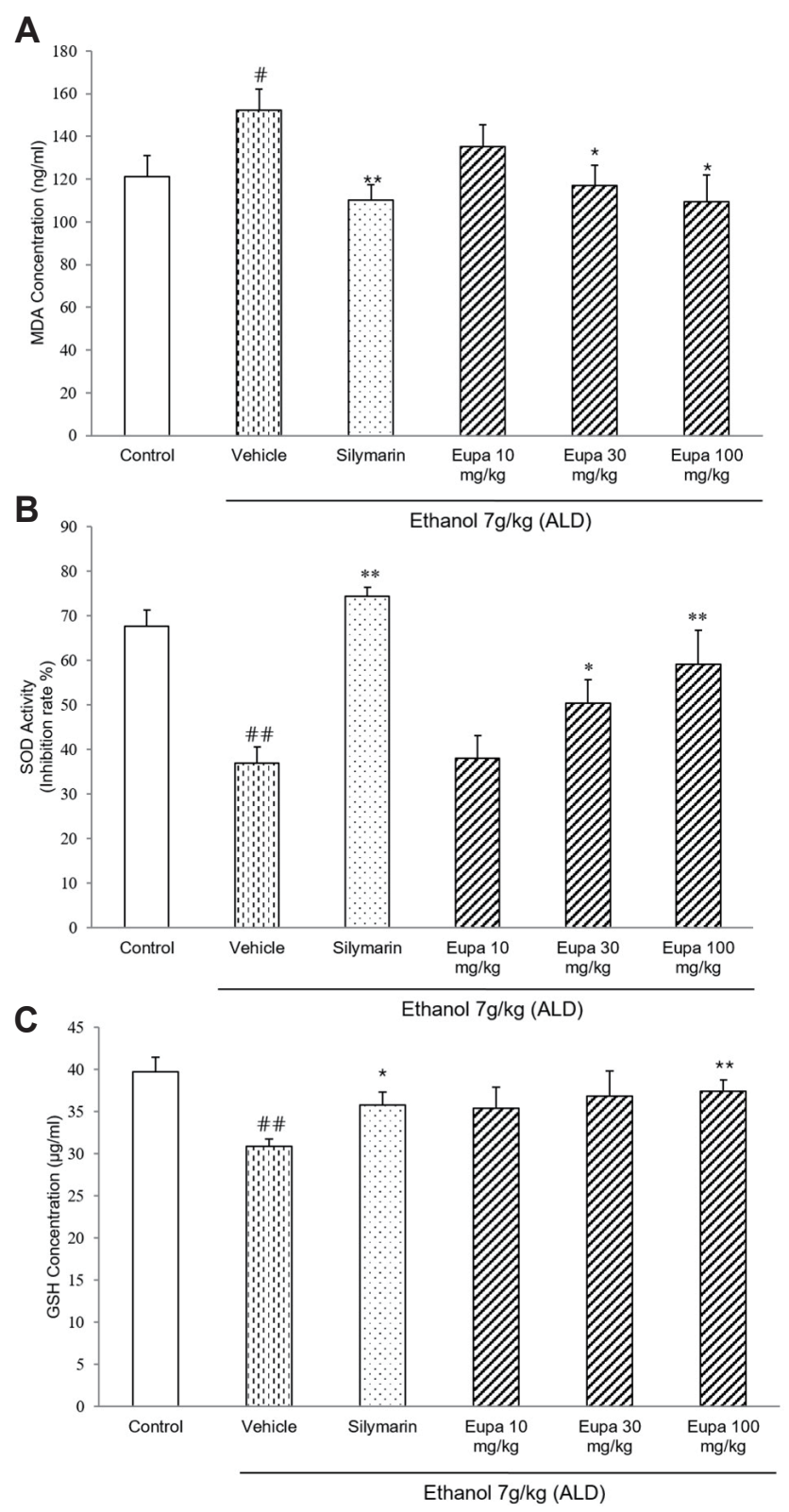

Fig. 4. Eupatilin reduced plasma MDA and improved antioxidant status in the ALD model. The activities of (A) MDA and (B) SOD and the level of (C) GSH were measured in rat plasma $(n=7)$. Control group: saline $+0.1 \%$ CMC-Na, vehicle group: $7 \mathrm{~g} / \mathrm{kg}$ ethanol $+0.1 \% \mathrm{CMC}-\mathrm{Na}$, silymarin (positive control) group: $7 \mathrm{~g} / \mathrm{kg}$ ethanol + silymarin $10 \mathrm{mg} / \mathrm{kg}$, eupatilin $10 \mathrm{mg} / \mathrm{kg}: 7 \mathrm{~g} / \mathrm{kg}$ ethanol + eupatilin $10 \mathrm{mg} / \mathrm{kg}$, eupatilin 30 $\mathrm{mg} / \mathrm{kg}: 7 \mathrm{~g} / \mathrm{kg}$ ethanol + eupatilin $30 \mathrm{mg} / \mathrm{kg}$, and eupatilin $100 \mathrm{mg} / \mathrm{kg}$ : $7 \mathrm{~g} / \mathrm{kg}$ ethanol + eupatilin $100 \mathrm{mg} / \mathrm{kg}$. Data are expressed as mean \pm standard error of the mean. CMC-Na, sodium carboxymethyl cellulose; ALD, alcoholic liver disease; MDA, malondialdehyde; SOD, superoxide dismutase; GSH, glutathione. $" p<0.05, " \# p<0.01$ vs. the control group, ${ }^{*} \mathrm{p}<0.05,{ }^{* *} \mathrm{p}<0.01$ vs. the vehicle group.

groups had lower levels of IL-1 $\beta$ than the vehicle group. In eupatilin $100 \mathrm{mg} / \mathrm{kg}$ group, IL-1 $\beta$ level was decreased with a similar level as the silymarin group. 

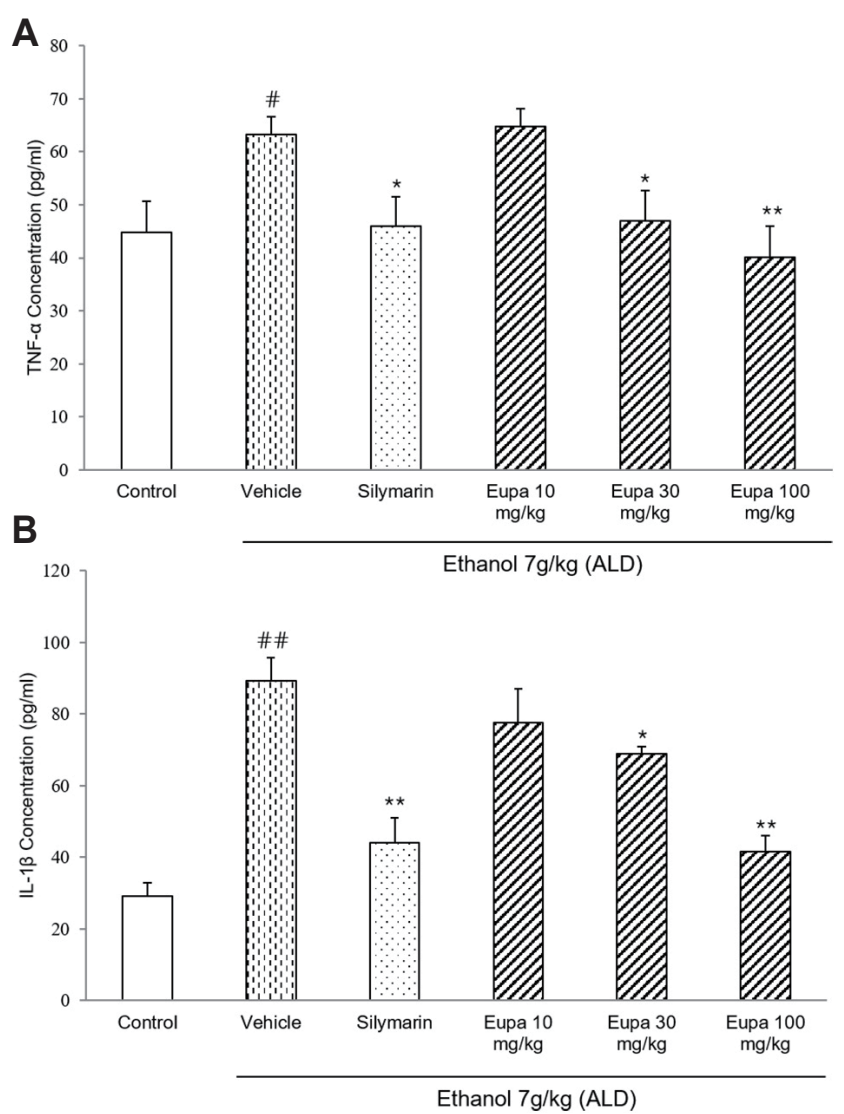

Fig. 5. Eupatilin exhibited an anti-inflammatory effect by reducing the level of inflammatory cytokines. (A) TNF- $\alpha$ and (B) IL-1 $\beta$ levels were measured in rat plasma $(n=7)$. Control group: saline $+0.1 \%$ CMC$\mathrm{Na}$, vehicle group: $7 \mathrm{~g} / \mathrm{kg}$ ethanol $+0.1 \% \mathrm{CMC}-\mathrm{Na}$, silymarin (positive control) group: $7 \mathrm{~g} / \mathrm{kg}$ ethanol + silymarin $10 \mathrm{mg} / \mathrm{kg}$, eupatilin $10 \mathrm{mg} /$ $\mathrm{kg}: 7 \mathrm{~g} / \mathrm{kg}$ ethanol + eupatilin $10 \mathrm{mg} / \mathrm{kg}$, eupatilin $30 \mathrm{mg} / \mathrm{kg}: 7 \mathrm{~g} / \mathrm{kg}$ ethanol + eupatilin $30 \mathrm{mg} / \mathrm{kg}$, and eupatilin $100 \mathrm{mg} / \mathrm{kg}: 7 \mathrm{~g} / \mathrm{kg}$ ethanol + eupatilin $100 \mathrm{mg} / \mathrm{kg}$. Data are expressed as mean \pm standard error of the mean. CMC-Na, sodium carboxymethyl cellulose; ALD, alcoholic liver disease; TNF, tumor necrosis factor; IL, interleukin. $" \mathrm{p}<0.05,{ }^{\# \#} \mathrm{p}<$ 0.01 vs. the control group, ${ }^{*} p<0.05,{ }^{* *} p<0.01$ vs. the vehicle group.

\section{Eupatilin reduced oxidative stress and inflammation in the liver tissue}

The H\&E-stained photomicrographs of the liver sections of the control- and ethanol-treated rats from each group are presented in Fig. 6. No histological abnormalities were observed in the liver tissue of the control group. However, abnormal pathological features were observed in the vehicle group compared to the control group. Necrosis, fat accumulation, sinusoidal dilation, and the membrane boundary of cells were unclear due to the degeneration of liver cells. The silymarin group, which served as the positive control, showed similar characteristics to the control. Further, the histological features observed in the ALD model were decreased in the eupatilin group as the concentration increased. In particular, the $100 \mathrm{mg} / \mathrm{kg}$ group showed normal morphology of liver cells like the silymarin group.

\section{DISCUSSION}

ALD is the main cause of death around the world. Although the causes of ALD are not well established, some studies have revealed that alcohol-induced oxidative stress, hepatotoxicity, and the complex interactions involving alcohol metabolism, liver cells, and multiple cytokines can affect the progression of ALD [26]. The antioxidant and anti-inflammatory effects of eupatilin were examined in several studies $[15,17,27,28]$. Recently, pharmacokinetic study also performed to demonstrate its potential benefit for diverse applications. Eupatilin was rapidly absorbed and distributed to various tissues, including the liver, kidneys and small intestine [29]. However, studies on the role of eupatilin in chronic alcohol-induced liver damage have not been reported. The purpose of this study was to determine the antioxidant, antiinflammatory, and hepatoprotective effects of eupatilin in an ALD model.

The ALD model was established as described in previous studies and preliminary experiments $[26,30]$. When $4 \mathrm{~g} / \mathrm{kg}$ of ethanol was administered in the preliminary test, ALD was not satisfactorily induced. Thus, we increased the concentration of ethanol to 7 $\mathrm{g} / \mathrm{kg}$ in this experiment based on other previous studies [31-33].

Alcohol appears to markedly increase metabolism, ultimately resulting in energy burn [34]. In the present study, chronic alcohol ingestion was found to result in weight loss, thereby aligning with the result of a previous study [35]. Further, body weight was found to recover in the eupatilin $100 \mathrm{mg} / \mathrm{kg}$ group compared to the vehicle group, suggesting that eupatilin normalizes the changes in body weight in the ALD model. Liver cells contain large amounts of AST and ALT in their mitochondria and cytoplasm. Because of varying hepatic cell damages, such as chronic alcohol intake, the levels of ALT and AST are elevated in the plasma. Thus, the increase in AST and ALT are often employed as indicators of cellular damages and hepatic functional impairments [36]. ALT and AST levels in ALD model significantly increased compared with control. Compared with other previous studies, it showed significant changes, and also other indicators supported this study induced ALD model properly [37,38]. Alcohol ingestion also induced liver steatosis. Studies have shown that increased concentrations of plasma TG and TC are significantly related to the degree of hepatic steatosis. As a result, TG and TC were employed as indicators to assess the degree of hepatic steatosis [30,39]. AST and ALT levels were decreased in the eupatilin administration groups compared to the vehicle group. Such finding indicates that eupatilin is effective in the ALD model by reducing liver damage. Additionally, TG and TC levels were decreased in the eupatilin treatment groups compared to the vehicle group. Eupatilin was effective in the ALD model by reducing steatosis. Therefore, the protective effect of eupatilin on the ALD model was related to the reduction in liver damage and steatosis.

ALD is characterized by mitochondrial damage, increased lipid peroxidation, free radical production, and decreased hepatic anti- 


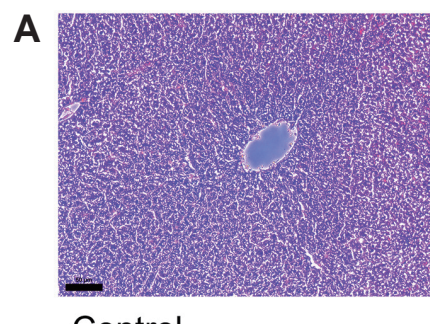

Control

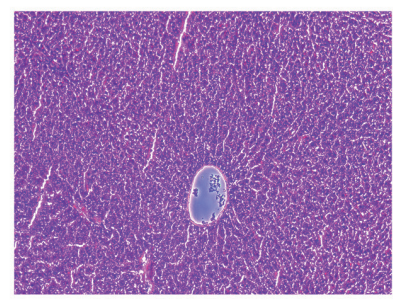

Eupa $10 \mathrm{mg} / \mathrm{kg}$

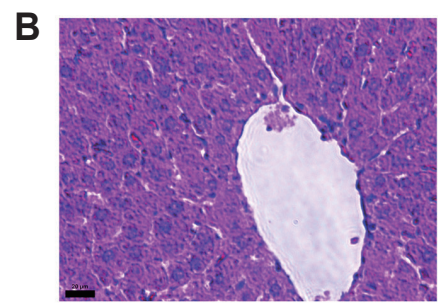

Control

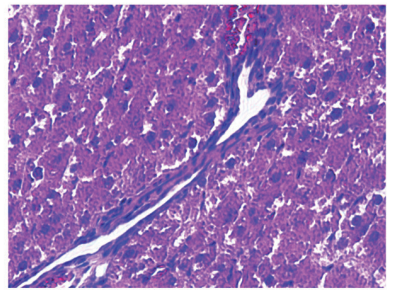

Eupa $10 \mathrm{mg} / \mathrm{kg}$

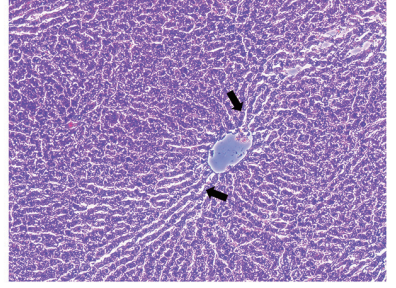

Vehicle

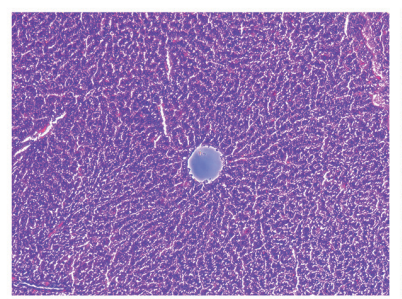

Eupa $30 \mathrm{mg} / \mathrm{kg}$

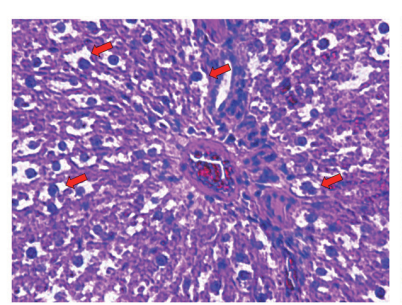

Vehicle

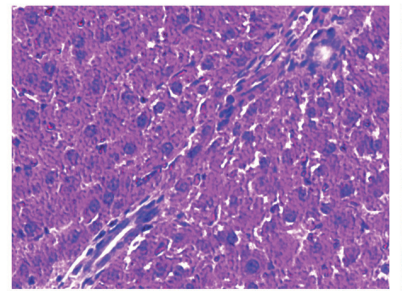

Eupa $30 \mathrm{mg} / \mathrm{kg}$

oxidant status [40]. MDA, one of the major secondary metabolites of lipid peroxidation after exposure to oxidative stress, such as free radicals and ROS, is used as an indicator of lipid peroxidation status [41]. An elevation in MDA levels demonstrates the enhancement in lipid peroxidation, thereby causing liver damage and impairment in the antioxidant defense systems to prevent the formation of immoderate free radicals [42]. According to previous studies, MDA levels are considerably increased in the plasma of rats treated with ethanol [43].

Impairment of the oxidative system leads to cellular damage by destroying their antioxidant components, such as SOD, the glutathione-related enzyme system [44]. SOD is a potent endogenous antioxidant enzyme. Thus, a lack of SOD results in an increase in oxidative stress, causing different pathologies in vivo $[45,46]$. GSH is a typical antioxidant molecule in the antioxidant defense mechanisms [47,48]. Several studies have suggested that both acute and chronic alcohol intake results in a decrease in SOD activity and GSH level $[49,50]$. The present study revealed that eupatilin could lower the MDA level and recover SOD activity and GSH level in

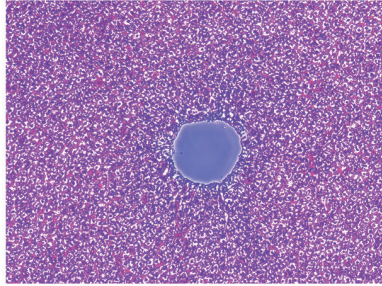

\section{Silymarin}

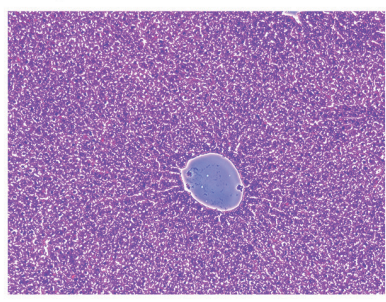

Eupa $100 \mathrm{mg} / \mathrm{kg}$

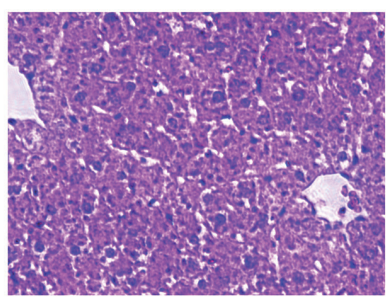

Silymarin

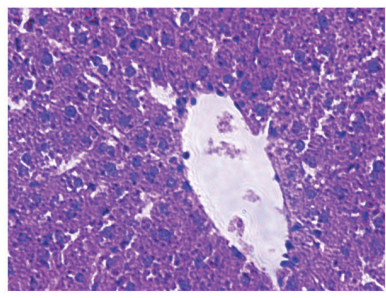

Eupa $100 \mathrm{mg} / \mathrm{kg}$
Fig. 6. Eupatilin reduced oxidative stress and inflammation in the liver tissue. H\&E-stained liver samples in the control, vehicle, silymarin (positive control), eupatilin $10 \mathrm{mg} / \mathrm{kg}$, eupatilin 30 $\mathrm{mg} / \mathrm{kg}$, and eupatilin $100 \mathrm{mg} / \mathrm{kg}$ groups. Representative photomicrographs of each sample were captured at (A) 20x (scale bar, $50 \mu \mathrm{m}$ ) and (B) 40× (scale bar, $20 \mu \mathrm{m}$ ) magnifications. The red arrow indicated the fat accumulation in liver tissue. The black arrow indicated sinusoidal dilation in liver tissue. Scale bar Control group: saline $+0.1 \%$ CMC-Na, vehicle group: $7 \mathrm{~g} / \mathrm{kg}$ ethanol + 0.1\% CMC-Na, silymarin (positive control) group: $7 \mathrm{~g} / \mathrm{kg}$ ethanol + silymarin $10 \mathrm{mg} / \mathrm{kg}$, eupatilin $10 \mathrm{mg} / \mathrm{kg}: 7 \mathrm{~g} / \mathrm{kg}$ ethanol + eupatilin 10 $\mathrm{mg} / \mathrm{kg}$, eupatilin $30 \mathrm{mg} / \mathrm{kg}: 7 \mathrm{~g} / \mathrm{kg}$ etha$\mathrm{nol}+$ eupatilin $30 \mathrm{mg} / \mathrm{kg}$, and eupatilin $100 \mathrm{mg} / \mathrm{kg}: 7 \mathrm{~g} / \mathrm{kg}$ ethanol + eupatilin $100 \mathrm{mg} / \mathrm{kg}$. CMC-Na, sodium carboxymethyl cellulose.

the plasma of the ALD model rats. The inhibitory effect of eupatilin on ALD could be attributed to anti-oxidation via reduced lipid peroxidation and restoration of the cellular antioxidant status.

TNF- $\alpha$ can activate T cells, macrophages, and major inflammatory cytokines, inducing immune responses and provoking the secretion of other inflammatory cytokines [51,52]. IL-1 $\beta$ is another inflammatory cytokine that is mainly released by macrophages, monocytes, and endothelial cells [53]. Because cytokines are crucial for inflammatory reactions, regulating their concentration can improve the therapeutic effect. The ALD model is characterized by the overproduction of inflammatory cytokines, TNF- $\alpha$ and IL-1 $\beta[54,55]$. In this study, eupatilin significantly reduced the concentrations of TNF- $\alpha$ and IL- $1 \beta$ in the plasma of the ALD model. Such findings demonstrate that eupatilin exhibits anti-inflammatory activity in the ALD model by reducing the levels of pro-inflammatory cytokines.

$\mathrm{H} \& \mathrm{E}$ staining was carried out to determine the alterations in the histological features of the liver [26]. Chronic ingestion of ethanol causes severe pathological damage in the liver, such as 
necrosis, inflammation, and tissue destruction [56]. Accordingly, necrosis of the hepatocytes, chromatin condensation, degeneration of the hepatocyte structure, and dilation of the sinusoid, were observed in the ALD model. However, following the administration of eupatilin $100 \mathrm{mg} / \mathrm{kg}$, these abnormal histological properties were improved as observed in the control or positive control group. Such findings demonstrate that eupatilin exhibits protective effects in the ALD model.

In conclusion, chronic ethanol-induced ALD occurs due to an increase in oxidative stress and inflammatory cytokines. We found that eupatilin has an anti-oxidative and anti-inflammatory effects which was demonstrated by the levels of MDA, TNF- $\alpha$, and IL-1 $\beta$, SOD activity and GSH level. These effects make eupatilin ameliorate liver cell damage and hepatic steatosis. These findings suggest that eupatilin can protect liver damage through its antioxidant and anti-inflammatory effects.

\section{ACKNOWLEDGEMENTS}

This research was supported by the Basic Science Research Program through the National Research Foundation of Korea funded by the Ministry of Education, Science and Technology (Grant NRF-2019R1F1A1062070) and the Chung-Ang University Graduate Research Scholarship in 2018.

\section{CONFLICTS OF INTEREST}

The authors declare no conflicts of interest.

\section{REFERENCES}

1. Doody EE, Groebner JL, Walker JR, Frizol BM, Tuma DJ, Fernandez DJ, Tuma PL. Ethanol metabolism by alcohol dehydrogenase or cytochrome P450 2E1 differentially impairs hepatic protein trafficking and growth hormone signaling. Am J Physiol Gastrointest Liver Physiol. 2017;313:G558-G569.

2. Siegmund SV, Dooley S, Brenner DA. Molecular mechanisms of alcohol-induced hepatic fibrosis. Dig Dis. 2005;23:264-274.

3. Goedde HW, Agarwal DP. [Alcohol metabolizing enzymes: biochemical properties, genetic heterogeneity and their possible role in alcohol metabolism in humans (author's transl)]. J Clin Chem Clin Biochem. 1981;19:179-189. German.

4. Li CJ, Nanji AA, Siakotos AN, Lin RC. Acetaldehyde-modified and 4-hydroxynonenal-modified proteins in the livers of rats with alcoholic liver disease. Hepatology. 1997;26:650-657.

5. Sapkota M, Hottor TK, DeVasure JM, Wyatt TA, McCaskill ML. Protective role of CYP2E1 inhibitor diallyl disulfide (DADS) on alcohol-induced malondialdehyde-deoxyguanosine (M1dG) adduct formation. Alcohol Clin Exp Res. 2014;38:1550-1558.

6. Niemelä O, Parkkila S, Ylä-Herttuala S, Halsted C, Witztum JL,
Lanca A, Israel Y. Covalent protein adducts in the liver as a result of ethanol metabolism and lipid peroxidation. Lab Invest. 1994;70:537546.

7. Kundu R, Dasgupta S, Biswas A, Bhattacharya A, Pal BC, Bandyopadhyay D, Bhattacharya S, Bhattacharya S. Cajanus cajan Linn. (Leguminosae) prevents alcohol-induced rat liver damage and augments cytoprotective function. J Ethnopharmacol. 2008;118:440447.

8. Song Z, Deaciuc I, Song M, Lee DY, Liu Y, Ji X, McClain C. Silymarin protects against acute ethanol-induced hepatotoxicity in mice. Alcohol Clin Exp Res. 2006;30:407-413.

9. Kojima H, Sakurai S, Uemura M, Takekawa T, Morimoto H, Tamagawa Y, Fukui H. Difference and similarity between nonalcoholic steatohepatitis and alcoholic liver disease. Alcohol Clin Exp Res. 2005;29(12 Suppl):259S-263S.

10. McCullough RL, McMullen MR, Sheehan MM, Poulsen KL, Roychowdhury S, Chiang DJ, Pritchard MT, Caballeria J, Nagy LE. Complement factor D protects mice from ethanol-induced inflammation and liver injury. Am J Physiol Gastrointest Liver Physiol. 2018;315:G66-G79.

11. Canbay A, Friedman S, Gores GJ. Apoptosis: the nexus of liver injury and fibrosis. Hepatology. 2004;39:273-278.

12. Han Y, Xu Q, Hu JN, Han XY, Li W, Zhao LC. Maltol, a food flavoring agent, attenuates acute alcohol-induced oxidative damage in mice. Nutrients. 2015;7:682-696.

13. Sun X, Wang P, Yao LP, Wang W, Gao YM, Zhang J, Fu YJ. Paeonol alleviated acute alcohol-induced liver injury via SIRT1/Nrf2/NF-кB signaling pathway. Environ Toxicol Pharmacol. 2018;60:110-117.

14. Jang HS, Um SI, Lee SH, Whang WK, Min YS, Park SY, Sohn UD. The protective mechanism of QGC in feline esophageal epithelial cells by interleukin-1 $\beta$ treatment. Arch Pharm Res. 2017;40:204-213.

15. Nageen B, Sarfraz I, Rasul A, Hussain G, Rukhsar F, Irshad S, Riaz A, Selamoglu Z, Ali M. Eupatilin: a natural pharmacologically active flavone compound with its wide range applications. J Asian Nat Prod Res. 2020;22:1-16.

16. Kim JS, Lee SG, Min K, Kwon TK, Kim HJ, Nam JO. Eupatilin inhibits adipogenesis through suppression of PPAR $\gamma$ activity in 3T3L1 cells. Biomed Pharmacother. 2018;103:135-139.

17. Kim M, Min YS, Sohn UD. Cytoprotective effect of eupatilin against indomethacin-induced damage in feline esophageal epithelial cells: relevance of HSP27 and HSP70. Arch Pharm Res. 2018;41:1019-1031.

18. Ryoo SB, Oh HK, Yu SA, Moon SH, Choe EK, Oh TY, Park KJ. The effects of eupatilin (stillen ${ }^{\circledR}$ ) on motility of human lower gastrointestinal tracts. Korean J Physiol Pharmacol. 2014;18:383-390.

19. Choi EJ, Oh HM, Na BR, Ramesh TP, Lee HJ, Choi CS, Choi SC, Oh TY, Choi SJ, Chae JR, Kim SW, Jun CD. Eupatilin protects gastric epithelial cells from oxidative damage and down-regulates genes responsible for the cellular oxidative stress. Pharm Res. 2008;25:13551364.

20. Yoo BM, Oh TY, Kim YB, Yeo M, Lee JS, Surh YJ, Ahn BO, Kim WH, Sohn S, Kim JH, Hahm KB. Novel antioxidant ameliorates the fibrosis and inflammation of cerulein-induced chronic pancreatitis in a mouse model. Pancreatology. 2005;5:165-176.

21. Zhou K, Cheng R, Liu B, Wang L, Xie H, Zhang C. Eupatilin ameliorates dextran sulphate sodium-induced colitis in mice partly through promoting AMPK activation. Phytomedicine. 2018;46:4656. 
22. Oh TY, Lee JS, Ahn BO, Cho H, Kim WB, Kim YB, Surh YJ, Cho SW, Hahm KB. Oxidative damages are critical in pathogenesis of reflux esophagitis: implication of antioxidants in its treatment. Free Radic Biol Med. 2001;30:905-915.

23. Ryu BK, Ahn BO, Oh TY, Kim SH, Kim WB, Lee EB. Studies on protective effect of DA-9601, Artemisia asiatica extract, on acetaminophen- and CCl4-induced liver damage in rats. Arch Pharm Res. 1998;21:508-513.

24. Park SC, Yoon JH, Kim W, Gwak GY, Kim KM, Lee SH, Lee SM, Lee HS. Eupatilin attenuates bile acid-induced hepatocyte apoptosis. J Gastroenterol. 2006;41:772-778.

25. Parvez MK, Arbab AH, Al-Dosari MS, Al-Rehaily AJ, Alam P, Ibrahim KE, Alsaid MS, Rafatullah S. Protective effect of Atriplex suberecta extract against oxidative and apoptotic hepatotoxicity. Exp Ther Med. 2018;15:3883-3891.

26. Kim D, Kim GW, Lee SH, Han GD. Ligularia fischeri extract attenuates liver damage induced by chronic alcohol intake. Pharm Biol. 2016;54:1465-1473.

27. Yu K, Li XM, Xu XL, Zhang RY, Cong HL. Eupatilin protects against tumor necrosis factor- $\alpha$-mediated inflammation inhuman umbilical vein endothelial cells. Int J Clin Exp Med. 2015;8:2219122197.

28. Qiao Z, Xu YW, Yang J. Eupatilin inhibits the apoptosis in H9c2 cardiomyocytes via the Akt/GSK-3 $\beta$ pathway following hypoxia/ reoxygenation injury. Biomed Pharmacother. 2016;82:373-378.

29. Wang X, Ren J, Zhu S, Ren G, Wang L, Chen X, Qiu Z, Zhang C. Pharmacokinetics and tissue distribution of eupatilin and its metabolite in rats by an HPLC-MS/MS method. J Pharm Biomed Anal. 2018;159:113-118.

30. Adaramoye OA, Aluko A, Oyagbemi AA. Cnidoscolus aconitifolius leaf extract protects against hepatic damage induced by chronic ethanol administration in Wistar rats. Alcohol Alcohol. 2011;46:451458.

31. Araújo Júnior RF, Garcia VB, Leitão RF, Brito GA, Miguel Ede C, Guedes PM, de Araújo AA. Carvedilol improves inflammatory response, oxidative stress and fibrosis in the alcohol-induced liver injury in rats by regulating Kuppfer cells and hepatic stellate cells. PLoS One. 2016;11:e0148868.

32. Liu R, Chen QH, Ren JW, Sun B, Cai XX, Li D, Mao RX, Wu X, Li Y. Ginseng (Panax ginseng Meyer) oligopeptides protect against binge drinking-induced liver damage through inhibiting oxidative stress and inflammation in rats. Nutrients. 2018;10:1665.

33. Ilaiyaraja N, Khanum F. Amelioration of alcohol-induced hepatotoxicity and oxidative stress in rats by Acorus calamus. J Diet Suppl. 2011;8:331-345.

34. Liangpunsakul S, Crabb DW, Qi R. Relationship among alcohol intake, body fat, and physical activity: a population-based study. Ann Epidemiol. 2010;20:670-675.

35. Rejitha S, Prathibha P, Indira M. Amelioration of alcohol-induced hepatotoxicity by the administration of ethanolic extract of Sida cordifolia Linn. Br J Nutr. 2012;108:1256-1263.

36. Hsieh YL, Yeh YH, Lee YT, Huang CY. Protective effects of Cholestin on ethanol induced oxidative stress in rats. J Sci Food Agric. 2015;95:799-808.

37. Huang H, Lin Z, Zeng Y, Lin X, Zhang Y. Probiotic and glutamine treatments attenuate alcoholic liver disease in a rat model. Exp Ther Med. 2019;18:4733-4739.
38. Zhou J, Zhang J, Wang C, Qu S, Zhu Y, Yang Z, Wang L. Açaí (Euterpe oleracea Mart.) attenuates alcohol-induced liver injury in rats by alleviating oxidative stress and inflammatory response. Exp Ther Med. 2018;15:166-172.

39. Lee IS, Park S, Park K, Choue R. Hepatoprotective activity of scutellariae radix extract in mice fed a high fat diet with chronic alcohol exposure. Phytother Res. 2011;25:1348-1353.

40. Radosavljević T, Mladenović D, Vucević D. [The role of oxidative stress in alcoholic liver injury]. Med Pregl. 2009;62:547-553. Serbian.

41. Cai Z, Shi T, Zhuang R, Fang H, Jiang X, Shao Y, Zhou H. Protective effect of $\mathrm{N}$-acetylcysteine activated carbon release microcapsule on myocardial ischemia-reperfusion injury in rats. Exp Ther Med. 2018;15:1809-1818.

42. Zhang C, Shi S. Physiological and proteomic responses of contrasting alfalfa (Medicago sativa L.) varieties to PEG-induced osmotic stress. Front Plant Sci. 2018;9:242.

43. Turan A, Celik I. Antioxidant and hepatoprotective properties of dried fig against oxidative stress and hepatotoxicity in rats. Int J Biol Macromol. 2016;91:554-559.

44. Ma J, Li M, Kalavagunta PK, Li J, He Q, Zhang Y, Ahmad O, Yin H, Wang T, Shang J. Protective effects of cichoric acid on $\mathrm{H}_{2} \mathrm{O}_{2}$-induced oxidative injury in hepatocytes and larval zebrafish models. Biomed Pharmacother. 2018;104:679-685.

45. Muller FL, Song W, Liu Y, Chaudhuri A, Pieke-Dahl S, Strong R, Huang TT, Epstein CJ, Roberts LJ 2nd, Csete M, Faulkner JA, Van Remmen H. Absence of CuZn superoxide dismutase leads to elevated oxidative stress and acceleration of age-dependent skeletal muscle atrophy. Free Radic Biol Med. 2006;40:1993-2004.

46. García-Niño WR, Zatarain-Barrón ZL, Hernández-Pando R, VegaGarcía CC, Tapia E, Pedraza-Chaverri J. Oxidative stress markers and histological analysis in diverse organs from rats treated with a hepatotoxic dose of Cr(VI): effect of curcumin. Biol Trace Elem Res. 2015;167:130-145.

47. Deng Y, Xu Z, Xu B, Liu W, Feng S, Yang T. Antioxidative effects of schidandrin $\mathrm{B}$ and green tea polyphenols against mercuric chlorideinduced hepatotoxicity in rats. J Environ Pathol Toxicol Oncol. 2014;33:349-361.

48. Perdices L, Fuentes-Broto L, Segura F, Ben Gdara N, SánchezCano AI, Insa G, Orduna E, Pinilla I. Hepatic oxidative stress in pigmented $\mathrm{P} 23 \mathrm{H}$ rhodopsin transgenic rats with progressive retinal degeneration. Free Radic Biol Med. 2018;124:550-557.

49. Li YG, Ji DF, Chen S, Hu GY. Protective effects of sericin protein on alcohol-mediated liver damage in mice. Alcohol Alcohol. 2008; 43:246-253.

50. Mallikarjuna K, Shanmugam KR, Nishanth K, Wu MC, Hou CW, Kuo CH, Reddy KS. Alcohol-induced deterioration in primary antioxidant and glutathione family enzymes reversed by exercise training in the liver of old rats. Alcohol. 2010;44:523-529.

51. Park SW, Oh TY, Kim YS, Sim H, Park SJ, Jang EJ, Park JS, Baik HW, Hahm KB. Artemisia asiatica extracts protect against ethanolinduced injury in gastric mucosa of rats. J Gastroenterol Hepatol. 2008;23:976-984.

52. Joo M, Kim HS, Kwon TH, Palikhe A, Zaw TS, Jeong JH, Sohn UD. Anti-inflammatory effects of flavonoids on TNBS-induced colitis of rats. Korean J Physiol Pharmacol. 2015;19:43-50.

53. Palenski TL, Sorenson CM, Sheibani N. Inflammatory cytokinespecific alterations in retinal endothelial cell function. Microvasc 
Res. 2013;89:57-69.

54. Lin HZ, Yang SQ, Zeldin G, Diehl AM. Chronic ethanol consumption induces the production of tumor necrosis factor-alpha and related cytokines in liver and adipose tissue. Alcohol Clin Exp Res. 1998;22(5 Suppl):231S-237S.

55. Kim YD, Lee KM, Hwang SL, Chang HW, Kim KJ, Harris RA, Choi HS, Choi WS, Lee SE, Park CS. Inhibition of cereblon by fenofibrate ameliorates alcoholic liver disease by enhancing AMPK. Biochim Biophys Acta. 2015;1852:2662-2670.

56. Zhang Y, Wang C, Yu B, Jiang JD, Kong WJ. Gastrodin protects against ethanol-induced liver injury and apoptosis in HepG2 cells and animal models of alcoholic liver disease. Biol Pharm Bull. 2018;41:670-679. 